training of participants, possibly offering one early on and again in the final year of training.

Offering an experiential learning event in the context education \& training of a wider training that is very much about achieving predetermined benchmarks creates the need for a rapid re-orientation in the membership. The participants were, on the whole, highly sophisticated, with a degree of self-awareness and capacity for critical reflection. Most had been in personal therapy as part of their training. While it remains to be explored how useful such an approach might be in the training of other professionals, this training model may contribute to the achievement of core and general competencies for all trainee psychiatrists.

\section{Acknowledgements}

We thank Dr Sheena Pollet for comments on the manuscript. Thanks also to the other members of the Organising Committee and to Asher Giora, Secretary of the Specialist Registrars in Psychotherapy Peer Group.

\section{Declaration of interest}

S.B. is Regional Development Officer for Consultancy Training and organising tutor of an MA programme, Psychoanalytic Approaches to Consultation and the
Organisation, offered by the Tavistock and Portman NHS Trust. She has received payment for directing group relations conferences.

\section{References}

DEAN, A. (2003) Mentors for newly appointed consultants. Advances in Psychiatric Treatment, 9, 164-165.

KHALEELEE, O. (2003) Learning from experience and the experience of learning in Group Relations

Conferences. In Group Relations Conferences. Reviewing and Exploring Theory, Design, Role-Taking and Application (eds. L. Bruner, A. Nutkevitch \& M. Sher). Karnac Books.

MILLER, E. J. (1990) Experiential learning in groups $\mathrm{I}$ : The development of the Leicester model. InThe Social Engagement of Social Science: A Tavistock Anthology: The SocioPsychological Perspective. Vol. 1 (eds. Trist \& H. Murray). FreeAssociation Books.

PFEIFFER, J.W. \& BALLEW, A. C. (1988) Using Structured Experiences in Human Resource Development. University AssociatesTT Series, Vol. 1. University Associates.

ROYAL COLLEGE OF PSYCHIATRISTS (2006) A Competency Based Curriculum for Specialist Training in Psychiatry, Core and General Module. Royal College of Psychiatrists (http:// www.rcpsych.ac.uk/PDF/ Curriculum $\% 20-\% 20$ core $\% 20$ and $\% 20$ general\%20module.pdf).

WILKIE, G. \& RAFFAELLI, D. (2005) In at the deep end: making the transition from SpR to consultant. Advances in Psychiatric Treatment, 11, 107-114.

*Sandy Bryson Regional Development Officer for ConsultancyTraining, Tavistock and Portman NHS Trust, and Principal Psychotherapist, Liverpool Psychotherapy and Consultation Service, Mossley Hill Hospital, Liverpool L18 8BU, email: sandy.bryson@merseycare.nhs.uk, Carolyn Asher Specialist Registrar in Psychotherapy, Liverpool Psychotherapy and Consultation Service, Mossley Hill Hospital

\title{
A development programme for newly appointed consultants
}

We developed a programme to help newly appointed consultants cope better with the difficulties they may encounter in their new role. The course was run in a large mental health trust which had been formed by the merger of two trusts 3 years before, as there had been some concerns there about the newly appointed consultants floundering when it came to understanding how the trust and the National Health Service (NHS) operated.

The course itself was based on the principles of 'action in learning' which are described below. It ran over a period of 10 months and 12 newly appointed consultants were invited to attend. The course evaluation suggested that participants valued the course and that it had met many of the objectives initially laid out. Course attendance was good and the group decided to continue meeting on a less formal basis.

The training to become a consultant psychiatrist is expensive and lengthy. Despite this, relatively little effort is put into ensuring that newly appointed consultants are supported in what is acknowledged as a difficult time for them (Houghton et al, 2002). Their appointment is an achievement in itself, but the expectations from colleagues and supervisors, as well as their own ambitions, can be overwhelming. Their initial enthusiasm for the job can be diminished, however, by system inertia or the obstacles they may face when attempting to implement their ideas.

With this in mind, a programme was developed (The Consultant Development Programme) to help new consultants work through this initial period as well as providing the basic building blocks to enable them take on future management leadership roles.

The programme was instituted in Birmingham and Solihull Mental Health Trust for several reasons: new consultants were not fully engaging in the management of the Trust; the Trust wanted all staff members to have a better understanding and knowledge of the workings of the Trust in order, at least for some, to be able to take on positions with management duties; the strategic health authority had made a sum of money available for 'management training' for consultants. 


\section{Objectives}

The programme was based on the principles of action learning - 'comrades in adversity' working together to solve problems (Revans, 1998). Action learning is an educational process that provides a framework for individuals to identify and solve problems in a group setting. Participants work in small groups called action learning sets. Each person reviews the actions they have taken and reflects on them in the group. By asking questions the group is able to clarify where the problems lie and where knowledge is lacking. The group then suggests potential solutions so that action can be taken to remedy the problem.

Newly appointed consultants (i.e. those in their first year or so of consultancy) can be seen as undergoing a 'leadership passage', a critical crossroads in their career that can provide huge opportunities for growth and development (Dottlich et al, 2004). This is an experience both shared with others in a similar position and unique to each individual. This programme was designed to bring newly appointed consultants in the Birmingham and Solihull Mental Health Trust together, to share experiences, and to learn with and from each other and from experienced consultants, medical managers and other senior NHS managers. It included updates on health policy and NHS organisation and structure, exploration of and practice in relevant behavioural skills, and reflective sessions designed to learn as much as possible from actual experience in the job. More specifically the objectives of the programme were:

- To explore the expectations placed on NHS consultants.

- To learn about various challenges a consultant faces through mutual reflection and discussion with experienced colleagues, managers and others.

- To update knowledge about national and local NHS policy, plans, organisation and structure.

- To have an opportunity to practice and develop some of the interpersonal skills associated with individual effectiveness in a consultant role.

The Trust had recently introduced a compulsory 2-day induction scheme for newly appointed consultants because of concerns that they were not fully aware of how the Trust operated. The 'development programme' was designed and run in conjunction with the Trust's induction and attendance was entirely voluntary. It was accredited for continuing professional development and participants were encouraged to fit this into their personal development plans and discuss this at their appraisals.

\section{The Consultant Development Programme}

The programme was built around three interlinked themes:

1. Context and governance of the health service. This was mainly a summary of how the health system is changing, how things are organised and how they work in practice (or not). Examples of this would include:
- an update on the current NHS policy, the NHS Plan and structural changes

- the primary-secondary care interface; commissioning

- local trust and health economy organisation

- resource allocation processes and money flows.

2. Self-development and interpersonal effectiveness 'me', my impact and effectiveness. This was designed to facilitate self-insight, self-development and how one's style and behaviour affect others. Examples would include:

- exploration of one's individual style of leadership using appropriate psychometrics

- linking this to the research and literature on leadership

- effective team-working behaviours

- managing meetings

- negotiating effectively.

3. Working in the system - medical management roles and putting knowledge and skills into practice in different organisational situations. This was the integration of the above two themes and was enabled through:

- structured reflection on and analysis of the actual experiences of the participants (the Chatham House Rule was applied, see below for further details)

- hearing from more experienced medical and other senior managers - 'how it was for me' and 'how I see it now'

- an introduction to techniques for deconstructing and reconstructing clinical services to effect improvements

- negotiating resources and developments - how the system works.

\section{Style}

The programme was interactive and experiential with a limited amount of didactic input. Participants were expected to contribute from their own experiences, to look for opportunities to apply what they have learned, and to support and challenge each other in learning and developing through the programme. Because of this open and interactive ethos it is important to respect individual confidences, namely to sign up to the Chatham House Rule: 'when a meeting, or part thereof, is held under the Chatham House Rule, participants are free to use the information received, but neither the identity nor the affiliation of the speaker(s), nor that of any other participant, may be revealed' (www.chathamhouse.org. uk/about/chathamhouserule/).

\section{Running the programme}

The formal programme ran from October 2006 to June 2007, with a cohort of 12 consultants of whom 10 attended regularly. The days were facilitated by two of the authors, P.S. and H.F. The event began with a key note speaker and finished with an informal dinner to enable the group to get to know one another. The next meeting took place the following day and had a 
Table 1. Course evaluation

education \& training

\begin{tabular}{ll} 
Item & Mean \\
score & \\
\hline
\end{tabular}

Increased understanding of the NHS policy and

the political context

Awareness of factors affecting the Trust management

Enhanced understanding of the role of the

clinician in management

Better grasp of the commissioning process

Foundation Trust status and its implications

Greater awareness of the role of other colleagues

Better appreciation of budget management

Awareness of my own personal strengths and

weakness

1. The score on a 7-point Likert scale (1 - strongly disagree, 7 - strongly agree).

'diagnostic' character - the group discussed the issues they felt were important and set an agenda for future events. A further 5 days of events (dates agreed with participants) were then scheduled. Box 1 outlines the content of the sessions; there was a mix of speakers, with some drawn from within the Trust and some external speakers of national renown.

\section{Course evaluation}

At the end of the course the participants were asked to complete its evaluation. A 7-point Likert scale was used and the consultants were asked to rate their responses to statements (Table 1) about what the course had helped them achieve. A score of 7 indicated strong agreement with the statement and high levels of satisfaction; the nearer the mean score is to 7 the better the evaluation. There was a generally high level of support for the course. For 10 of the 12 consultants to attend regularly was considered to be a considerable achievement.

\section{Box 1. The Consultant Development Programme}

The first two sessions comprised: introduction by theTrust CEO, introduction to learning sets, determining agenda and agreeing development plans.

Further five day events covered:

- developing a business case for one's service - theory and practice

- medical leadership and professionalism (external speaker from the NHS Institute for Innovation and Improvement)

- understanding finance (by the director of finance) and also the medical director giving his views on the issues facing consultants

- teamwork

- commissioning in the NHS (the speaker was the director of commissioning from a non-local trust)

- clinical leadership - role and expectations

- service improvement in mental health services (by Deputy National Director for Mental Health)

- negotiating skills
Because this was the first time that the Trust had run such a course some of the 'new' consultants had in fact been in the Trust for up to 3 years and it was felt they would have benefited from attending such a course earlier.

It is likely that the action-learning framework of the course which encouraged participants to identify their learning needs contributed significantly to the high degree of commitment to and satisfaction with the course.

\section{Future developments}

The group agreed that they wished to continue to meet and have arranged further four sessions. The cost of the course was met by one-off funding for consultant management development from the West Midlands Strategic Health Authority. Because of the positive feedback on the course, the Trust have agreed to fund another programme for consultants who have been appointed since (it was scheduled for January 2008). In terms of the impact of the programme it will be important to see how the consultants engage with management issues in the broader sense and how much at ease they feel with this area of their working lives. A further questionnaire in 1- or 2-years time may give a better sense of whether the programme has had a lasting impact.

The aim of this programme was not to produce medical managers but rather to ensure that clinicians had a better understanding of the management issues that affect their ability to look after patients. It is of vital importance that psychiatrists are involved in medical management (Griffiths \& Readhead, 2006). By giving consultants a basic understanding of the issues involved in management it is possible that they will be able to have both a good relationship with managers essential to delivering high-quality patient care (Garelick \& Fagin, 2005) and also to be able to give informed consideration as to whether or not they wish to be the medical managers of the future.

\section{Declaration of interest}

None.

\section{References}

DOTTLICH, D., NOEL, J. \& WALKER, N. (2004) Leadership Passages: The Personal and Professional Transitions That Make or Break a Leader. JosseyBass.

GARELICK, A. \& FAGIN, L. (2005) The doctor-manager relationship. Advances in Psychiatric Treatment, 11, $241-250$

GRIFFITHS, H. \& READHEAD, E. (2006) Medical managers in psychiatry - vital to the future. Psychiatric Bulletin, 30, 201-203.

HOUGHTON, A., PETERS, T. \& BOLTON, J. (2002) What do new consultants have to say? BMJ, 325, S145.

REVANS, R.W. (1998) ABC of Action Learning. Lemos \& Crane.

Peter Spurgeon Health Services Management, Medical School, University of Warwick, Coventry, ${ }^{*}$ Christopher A Vassilas Consultant Psychiatrist, Birmingham and Solihull Mental HealthTrust, Queen Elizabeth Psychiatric Hospital, MindelsohnWay, Birmingham B15 2QZ, email: c.a.vassilas@bham.ac.uk, Hugh Flanagan Director, Organisational Research and Consultancy (International), Newport 